\title{
Kadın Bireylerde Besin Bağımlılığının Değerlendirilmesi
}

\section{Evaluation of Food Addiction in Female Individuals}

\author{
Sümeyye Güzel ${ }^{1 *}$, Alev Keser $^{1}$ \\ ${ }^{1}$ Ankara Üniversitesi Sağlık Bilimleri Fakültesi Beslenme ve Diyetetik Bölümü, Ankara, Türkiye \\ e-mail: sumeyyeguze191@ @otmail.com, akeser@ankara.edu.tr \\ ORCID: 0000-0001-6974-8461 \\ ORCID: 0000-0003-2620-6747 \\ *Sorumlu Yazar/ Corresponding Author: Sümeyye Güzel \\ Gönderim Tarihi / Received: 17.04.2020 \\ Kabul Tarihi / Accepted: 30.11.2020 \\ DOI: $10.34087 /$ cbusbed.722083
}

\begin{abstract}
Giriş ve Amaç: Besin bağımlılı̆̆ı; bireyler tarafından lezzetli kabul edilen ve yüksek enerji/yağ/şeker içeren besinlerin bağımlılık yapıcı etkilerinden dolayı aşırı yemeye neden olarak obezite etiyolojisinde rol oynayabileceği düşüncesi ile son yıllarda oldukça ilgi çeken bir konu haline gelmiştir. Bu çalışma, kadın bireylerde besin bağımlılığ görülme sıklığının belirlenmesi ve besin bağımlılı̆̆ı ile antropometrik ölçümler ve biyokimyasal parametreler arasındaki ilişkinin değerlendirilmesi amacıyla yürütülmüştür.

Gereç ve Yöntemler: Çalışmaya 19-64 yaş arası 106 gönüllü kadın birey katılmıştır. Kadınların vücut analizleri, segmental vücut analiz cihazı ile belirlenirken besin bağımlılığı durumu Yale Besin Bağımlılığı Ölçeği ile değerlendirilmiştir.

Bulgular: Araştırmaya katılan bireylerin \%26.4'ünde besin bağımlılı̆̆ olduğu belirlenmiştir. Bireylerin besin bağımlılığına sahip olma durumuna göre antropometrik ölçümleri ve biyokimyasal parametreleri arasında istatistiksel olarak anlamlı farklılık bulunmazken besin bağımlılığı olan kadınlarda fazla kilolu ve obez olma oranının, bel çevresi, bel/kalça oran1, toplam kolesterol, LDL-kolesterol ve trigliserit düzeyleri için riskin daha yüksek olduğu belirlenmiştir ( $\mathrm{p}>0.05)$. Bununla birlikte besin bağımlılığına sahip kadınların olmayanlara kıyasla daha sık fast-food tarzı besin ve şekerli içecek tükettikleri saptanmıştır $(\mathrm{p}<0.05)$.

Sonuç: Besin bağımlılığı, kadınlar arasında yaygın olmakla birlikte kardiyometabolik hastalıklar için risk faktörü kabul edilen bazı parametreler üzerinde olumsuz etkilere sahiptir. $\mathrm{Bu}$ durum; besin bağımlılığının obezite, kardiyovasküler hastalıklar, metabolik sendrom ve diyabet gibi hastalıkların görülme sıklığının artmasında rol oynayabileceğini göstermektedir.
\end{abstract}

Anahtar Kelimeler: Antropometrik ölçümler, Besin bağımlılığı, obezite, Yale Besin Bağımlılığı Ölçeği

\footnotetext{
Abstract

Objective: Food addiction; due to the addictive effects of foods that are considered delicious by individuals and contain high energy/fat/sugar, it has become a subject of interest in recent years with the idea that it may play a role in the etiology of obesity by causing overeating. This study was conducted to determine the frequency of food addiction in female individuals and to evaluate the relationship between food addiction and anthropometric measurements and biochemical parameters.

Materials and Metods: 106 volunteer female individuals aged 19-64 participated in the study. While body analyzes of women were determined with segmental body analysis device, nutritional addiction status was evaluated by Yale Food Addiction Scale.

Results: It was determined that $26.4 \%$ of the individuals participating in the research had food addiction. While there was no statistically significant difference in anthropometric measurements and biochemical parameters of individuals according to their food addiction status, it is determined that being overweight and obese and the risk for waist circumference, waist/hip ratio, total cholesterol, LDL-cholesterol and triglyceride levels are higher in women with food addiction ( $p>0.05)$. However, it was found that women with food addiction consumed fast food and sugar sweetened drinks more frequently than those who did not $(\mathrm{p}<0.05)$.
} 
Conclusion: Food addiction is common among women and it has negative effects on some parameters that are accepted as risk factors for cardiometabolic diseases. This situation; shows that food addiction may play a role in increasing the incidence of diseases such as obesity, cardiovascular diseases, metabolic syndrome and diabetes.

Key Words: Anthropometric measurements, Food addiction, Obesity, Yale Food Addiction Scale

\section{Giriș}

Dünya Sağlık Örgütü (DSÖ), 2016 yılında 18 yaş ve üzeri bireylerin \%39'unun fazla kilolu, \%13'ünün obez olduğunu rapor etmiştir [1]. Klinik araştırmalar ve uygulanan politikalara rağmen obezite görülme sıklığı artmaya devam etmekte ve bu durum obeziteye bağlı gelişen kronik hastalıkların mortalite oranının artmasına neden olmaktadır [2]. Bu bağlamda obezitenin dünya genelinde epidemi haline gelmesi, obezite ile mücadele için etkili stratejilerin geliştirilmesini gerekli kılmaktadır [3].

Enerji yoğunluğu yüksek olan besinlerin fazla miktarda tüketilmesi, pozitif enerji dengesi ve haz duygusu oluşturarak obezite gelişiminde önemli bir rol oynamaktadır [4]. Yüksek düzeyde işlenmiş ve yoğun enerji içeriğine sahip besin tüketiminin, beynin ödül sisteminde ve nörotransmitter yolaklarda işlevsel değişimlere neden olabileceği belirtilmektedir [5]. Bu değişikliklerle birlikte beyinde serbest kalan endojen opioid düzeyinin artması, besinlerin tüketim isteğini artırarak süreci kısır döngüye sokmakta ve vücut ağırlığının artmasına neden olmaktadır [2]. Yağ, tuz ve/veya şeker içeriği yüksek besinlerin daha fazla bağımlılık benzeri yeme davranışına neden olduğu ve besin bağımlılığı gelişen bireylerin, madde kullanım bozuklukları olan kişilerde görülen dürtüsellik, bozulmuş kontrol, fonksiyonel bozukluk ve geri çekilme gibi davranışsal özelliklere sahip olduğu ifade edilmektedir $[5,6]$. Bu konuya ilişkin olarak ilk kez 1950'li yıllarda 'besin bağımlılığı' kavramı ortaya atılmıştır [7]. Besin bağımlılığı, kontrol kaybı ve aşırı yeme isteği sonucunda fazla miktarda besin tüketimi olarak tanımlanmaktadır [8]. Bu nedenle besin tüketiminin kontrolsüz bir şekilde artmasında etkili bir faktör olan besin bağımlılığının incelenmesi önem kazanmaktadır [3]. Toplumdaki bireylerin yaklaşık \%5-10'unun besin bağımlılığına sahip olduğu ve besin bağımlılığı görülme sıklığının obez ve tıkanırcasına yeme bozukluğu olan bireylerde daha yüksek olduğu ifade edilmektedir [9]. Bu bağlamda, ödül ve haz ile ilgili yolakların anlaşılmasının, yeme davranışını düzeltmeye yönelik müdahalelerin geliştirilmesinde ve dolayısıyla obezitenin önlenmesi ve tedavisinde etkili olacağı düşünülmektedir [2].

$\mathrm{Bu}$ çalışma; obezite ve besin bağımlılı̆̆ ilişkinin incelenmesi, kadınlarda besin bağımlılığı görülme sıklığının saptanması, antropometrik ölçümler ve biyokimyasal parametrelerle besin bağımlılığ arasındaki ilişkinin değerlendirilmesi amacıyla yapılmıştır.

\section{Materyal ve Metod}

\subsection{Araştırmanın Tipi, Yapıldı̆̆ Yer ve Zaman}

Kesitsel tipte yağılan bu araştırma, 1-30 Kasım 2017 tarihleri arasında Isparta Binbirevler Aile Sağlığ Merkezi'nde yağılmıştır.

\subsection{Araştırmanın Evren ve Örneklemi}

Araştırmanın örneklemini, 1-30 Kasım 2017 tarihleri arasında Isparta Binbirevler Aile Sağlığı Merkezi'ne gelen 19-64 yaş arası 106 kadın birey oluşturmaktadır. Araştırmaya besin alımını etkileyebilecek hastalığı olan (kardiyovasküler hastalık, diyabet ve sistemik bozukluklar gibi) ve ilaç kullanan bireyler dahil edilmemiştir. Araştırmanın örneklem büyüklüğü hesabı G-Power programinda (3,0 versiyon) benzer bir çalışmadaki [10] değerler $(31,8 \pm 6,6$ ve $27,2 \pm 5,2)$ baz alınarak 0,05 anlamlılık düzeyi ve 0,95 güç ile yapıldığında en az 74 kişiden oluşan örneklemin bu araştırma için yeterli olacağı saptanmıştır.

2.3.Antropometrik Ölçümler ve Biyokimyasal Parametreler

Araştırmaya katılan bireylerin boy uzunluğu Seca marka boy ölçerle; vücut ağırlığ $1(\mathrm{~kg})$, vücut yağ yüzdesi (VYY, \%), yağsız vücut kütlesi (YVK, kg), bazal metabolizma hızı (BMH, kkal) ise 8-12 saatlik açlık sonrası hafif kıyafetlerle ve çıplak ayakla Tanita $545 \mathrm{~N}$ segmental vücut analiz cihazı ile belirlenmiştir. Bireylerin beden kütle indeksi (BKİ) değerleri vücut ağırlığı $(\mathrm{kg}) /$ boy uzunluğu $\left(\mathrm{m}^{2}\right)$ formülüyle hesaplanmıştır. Bel çevresi ve kalça çevresi ölçümleri tekniğine uygun bir şekilde alınmıştır. Bireylerin BKİ, bel çevresi ve bel/kalça oranı değerleri, DSÖ kriterlerine göre değerlendirilmiştir [11]. Bireylerin biyokimyasal verileri (açlık kan glukozu/AKG, toplam kolesterol/TK, düşük yoğunluklu lipoprotein kolesterol/LDL-K, yüksek yoğunluklu lipoprotein kolesterol/HDL-K, trigliserit/TG) Aile Sağlığı Merkezi kayıtlarından elde edilmiștir ve kan lipid profilleri Ulusal Kolesterol Eğitim Programı Yetişkinlerde Tedavi Paneli (NCEP-ATP) III sınıflandırmasına göre değerlendirilmiştir [12].

\subsection{Besin Bă̆ımlılı̆̆ının Değerlendirilmesi}

Bireylerin besin bağımlılığına sahip olma durumları Yale Besin Bağımlılığı Ölçeği (YFAS) ile belirlenmiştir. Yale Besin Bağımlılığı Ölçeği, son 12 ay içinde yüksek yağlı ve şekerli yiyeceklere karşı bağımlılık tarzı yeme davranışlarını ölçen, 25 maddeden oluşan ve kişinin kendi beyanına dayalı bir ölçektir. Mental Bozuklukların Tanısal ve İstatistiksel El Kitabı (DSM)-4'teki madde bağımlılığı kriterlerinin yedi semptomunun (tolerans, yoksunluk, klinik anlamlılık gibi) besin bağımlılığına uyarlanmasıyla oluşturulmuştur. Ölçeğin skorlaması, her bir bağımlılık kriterinin (tolerans, yoksunluk, klinik anlamlılık gibi) alt sorularına ait puanların toplamı ile yapılmıştır. Kriter skorunun $\geq 1$ olması durumunda kriterin karşılandığı; 15. ya da 16. maddelerden en az birinin 1 puan ve semptom skorunun $\geq 3$ olmas 1 durumunda klinik anlamlılığın sağlandığı; bu iki 
parametreden birinin sağlanmadığı durumda ise tanının olmadığı ya da karşılanmadığı kabul edilmiştir [13].

\subsection{Verilerin İstatistiksel Değerlendirilmesi}

Verilerin analizi SPSS programı ile yapılmıştır. Tanımlayıcı istatistikler dağılımı normal olan değişkenler için ortalama \pm standart sapma $(\mathrm{X} \pm \mathrm{SS})$, dağılımı normal olmayan değişkenler için ortanca ve çeyrekler arası fark (IQR) ile, nominal değişkenler ise vaka sayısı ve yüzdesi (\%) olarak gösterilmiştir. İki kategorik değişken arasındaki ilişki Ki-Kare testi; iki nicel değişken arasındaki farklılık, normal dağılım varsayımları sağlanıyorsa Independent t-testi, sağlanmıyorsa Mann-Whitney U testi ile saptanmıştır. Normal dağılım gösteren nicel değişkenler arasındaki farklılık Pearson Korelasyon, normal dağılım göstermeyenler ise Spearman Korelasyon Katsayısı ile belirlenmiştir. Tüm istatistiksel testlerde güven aralığ1
$\% 95,0$ olarak kabul edilmiş olup $\mathrm{p}<0,05$ anlamlılık düzeyinde değerlendirilmiştir.

\section{Bulgular ve Tartışma}

Araştırmaya katılan bireylerin çoğunluğunun $(\% 69,8)$ yaşları 30-59 yıl olup \%79,2'si evli, \%34,0'ü lise mezunu ve \%85,9'u herhangi bir işte çalıșmamaktadır. Bireylerin \%58,5'i günlük öğün sayısının üç olduğunu, \%95,3'ü ana öğünler dişında besin tükettiğini ifade etmiştir. Bununla birlikte bireylerin \%73,6'sının abur cubur tüketme ve \%33,0'ünün yemeğin tadına bakmadan tuz atma alışkanlığ 1 bulunmaktadır. Yale Besin Bağımlılığ Ölçeği'ne göre değerlendirme yapıldığında araştırmaya katılan bireylerin \%26,4'ünde (n:28) besin bağımlılı̆̆ olduğu belirlenmiştir. Besin bağımlılığı olan kadınların olmayanlara kıyasla fast-food tarzı besin ve şekerli içecek tüketme sıklıklarının daha fazla olduğu belirlenmiştir $(\mathrm{p}<0,05)$ (Tablo 1).

Tablo 1. Katılımcıların genel özellikleri

\begin{tabular}{|c|c|c|c|c|c|}
\hline 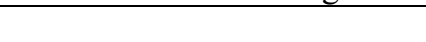 & \multicolumn{2}{|c|}{$\mathbf{S}$} & \multicolumn{3}{|c|}{$\%$} \\
\hline \multicolumn{6}{|l|}{ Yaş aralığı (yıl) } \\
\hline $19-29$ & \multicolumn{2}{|c|}{21} & \multicolumn{3}{|c|}{19,8} \\
\hline $30-49$ & \multicolumn{2}{|c|}{38} & \multicolumn{3}{|c|}{35,8} \\
\hline $50-59$ & \multicolumn{2}{|c|}{36} & \multicolumn{3}{|c|}{34,0} \\
\hline $60-64$ & \multicolumn{2}{|c|}{11} & \multicolumn{3}{|c|}{10,4} \\
\hline \multicolumn{6}{|l|}{ Medeni durum } \\
\hline Evli & \multicolumn{2}{|c|}{84} & \multicolumn{3}{|c|}{79,2} \\
\hline Bekar & \multicolumn{2}{|c|}{22} & \multicolumn{3}{|c|}{20,8} \\
\hline \multicolumn{6}{|l|}{ Eğitim Durumu } \\
\hline İlkokul & \multicolumn{2}{|c|}{34} & \multicolumn{3}{|c|}{32,1} \\
\hline Ortaokul & \multicolumn{2}{|c|}{22} & \multicolumn{3}{|c|}{20,8} \\
\hline Lise & \multicolumn{2}{|c|}{36} & \multicolumn{3}{|c|}{34,0} \\
\hline Lisans ve lisansüstü & \multicolumn{2}{|c|}{14} & \multicolumn{3}{|c|}{13,2} \\
\hline \multicolumn{6}{|l|}{ Lisansüstü } \\
\hline \multicolumn{6}{|l|}{ Çalışma Durumu } \\
\hline Çalışıor & \multicolumn{2}{|c|}{15} & \multicolumn{3}{|c|}{14,1} \\
\hline Çalışmıyor & & & & 85,9 & \\
\hline Tüketilen ana öğün sayısı & & & & & \\
\hline 1 öğün & & & & 0,9 & \\
\hline 2 öğün & & & & 40,6 & \\
\hline 3 öğün & & & & 58,5 & \\
\hline Ana öğünler dışında besin tüketimi & & & & & \\
\hline Evet & & & & 95,3 & \\
\hline Hayit & & & & 4,7 & \\
\hline Abur cubur tüketme alışkanlığı & & & & & \\
\hline Evet & & & & 73,6 & \\
\hline Hayır & & & & 27,4 & \\
\hline Yemeğin tadına bakmadan tuz atm & lşkanlığı & & & & \\
\hline Evet & & & & 33,0 & \\
\hline Hayır & & & & 67,0 & \\
\hline & $\begin{array}{c}\text { Besin bağımlılığı } \\
\operatorname{var}(\mathbf{n}: 28)\end{array}$ & $\begin{array}{c}\text { Besin bağımlılığı } \\
\text { yok (n:78) }\end{array}$ & Toplam (n:106) & & \\
\hline & $\begin{array}{c}\mathrm{X} \pm \mathrm{SS} \\
\text { Ortanca (IQR) }\end{array}$ & $\begin{array}{c}\mathrm{X} \pm \mathrm{SS} \\
\text { Ortanca (IQR) }\end{array}$ & $\begin{array}{c}\mathrm{X} \pm \mathrm{SS} \\
\text { Ortanca }(\mathrm{IQR})\end{array}$ & $\mathbf{z}$ & $\mathbf{p}^{\mathrm{a}}$ \\
\hline Fast-food tüketim sıklı̆ğ (hafta/kez) & $\begin{array}{l}1,4 \pm 1,68 \\
1,0(2,0)\end{array}$ & $\begin{array}{l}0,4 \pm 0,74 \\
0,0(1,0)\end{array}$ & $\begin{array}{l}0,6 \pm 1,15 \\
0,0(1,0)\end{array}$ & $-3,493$ & $0,000 *$ \\
\hline $\begin{array}{l}\text { Sekerli içecek tüketim sıklığ } \\
\text { (hafta/kez) }\end{array}$ & $\begin{array}{l}2,6 \pm 3,32 \\
2,0(5,0)\end{array}$ & $\begin{array}{l}0,7 \pm 1,79 \\
0,0(1,0)\end{array}$ & $\begin{array}{l}1,2 \pm 2,41 \\
0,0(1,0)\end{array}$ & $-2,533$ & $0,011 *$ \\
\hline
\end{tabular}

${ }^{\mathrm{a}}$ Mann Whitney U testi yapılmıştır. ${ }^{*} \mathrm{p}<0,05$ 
Besin bağımlılığı olan ve olmayan bireylerin YFAS toplam ölçek puanı ve alt ölçekleri karşılama durumu değerlendirildiğinde parametreler arasında istatistiksel olarak anlamlı bir farklılık olmadığ saptanmıştır (p>0,05) (Tablo 2).

Tablo 2. Katılımcıların YFAS toplam ölçek puanlarının ortalama, SS, ortanca, IQR değerleri ile YFAS alt ölçeklerini karşılama durumlarının dağılımları

\begin{tabular}{|c|c|c|c|c|c|c|c|c|}
\hline & \multicolumn{2}{|c|}{$\begin{array}{l}\text { Besin bağımlılığı } \\
\quad \operatorname{var}(\mathbf{n}: 28)\end{array}$} & \multicolumn{2}{|c|}{$\begin{array}{l}\text { Besin bağımlılığı } \\
\text { yok (n:78) }\end{array}$} & \multicolumn{2}{|c|}{ Toplam (n:106) } & & \\
\hline $\begin{array}{l}\mathrm{X} \pm \mathrm{SS} \\
\text { Ortanca (IQR) }\end{array}$ & \multicolumn{2}{|c|}{$\begin{array}{l}3,9 \pm 1,08 \\
4,0(2,00)\end{array}$} & \multicolumn{2}{|c|}{$\begin{array}{l}3,6 \pm 1,15 \\
4,0(1,00)\end{array}$} & \multicolumn{2}{|c|}{$\begin{array}{l}3,7 \pm 1,14 \\
4,0(1,00)\end{array}$} & $-1,123$ & $0,262^{\mathrm{a}}$ \\
\hline YFAS alt ölçekleri ${ }^{\alpha}$ & $\mathbf{S}$ & $\%$ & $\mathbf{S}$ & $\%$ & $\mathbf{S}$ & $\%$ & $\chi^{2}$ & p \\
\hline $\begin{array}{l}\text { Fazla yemeden dolayı halsiz veya yorgun } \\
\text { hissetme }\end{array}$ & 8 & 28,6 & 26 & 33,3 & 34 & 32,1 & 0,214 & $0,643^{\mathrm{b}}$ \\
\hline $\begin{array}{l}\text { Besin veya beslenme ile ilgili sorunların } \\
\text { fonksiyon yeteneğini azaltması }\end{array}$ & 21 & 75,0 & 62 & 79,5 & 83 & 78,3 & 0,244 & $0,621^{\mathrm{b}}$ \\
\hline $\begin{array}{l}\text { Yeme davranışının önemli sıkıntılara neden } \\
\text { olması }\end{array}$ & 24 & 85,7 & 62 & 79,5 & 86 & 81,1 & 0,522 & $0,470^{\mathrm{b}}$ \\
\hline $\begin{array}{l}\text { Belirli yiyecekleri fazla tüketmeden kaynaklı } \\
\text { olumsuz duygularla baș etme }\end{array}$ & 5 & 17,9 & 12 & 15,4 & 17 & 16,0 & 0,094 & $0,769^{\mathrm{c}}$ \\
\hline $\begin{array}{l}\text { Belirli yiyecekleri tüketmeme ile ilgili sorun } \\
\text { yaşama }\end{array}$ & 11 & 39,3 & 26 & 33,3 & 37 & 34,9 & 0,321 & $0,571^{\mathrm{b}}$ \\
\hline Fiziksel yoksunluk belirtileri & 19 & 67,9 & 37 & 47,4 & 56 & 52,8 & 3,448 & $0,063^{b}$ \\
\hline Aç olmadığı halde belirli yiyecekleri tüketme & 22 & 78,6 & 56 & 71,8 & 78 & 73,6 & 0,487 & $0,485^{\mathrm{b}}$ \\
\hline
\end{tabular}

${ }^{\alpha}$ Alt ölçekleri karşılayan bireylerin sayı ve yüzde bilgileri verilmiştir.

${ }^{a}$ Mann Whitney U testi ${ }^{\mathrm{b}}$ Pearson kikare ${ }^{\mathrm{c}}$ Likelihood kikare testi yapılmıştır. $* \mathrm{p}<0,05$

Araştırmaya katılan bireylerin besin bağımlılı̆̆ına sahip olma durumuna göre antropometrik ölçümler ve biyokimyasal parametreleri Tablo 3 'te gösterilmiştir. Bu tabloya göre besin bağımlılığı olan ve olmayan bireylerin antropometrik ölçümleri ve biyokimyasal bulguları arasında istatistiksel olarak anlamlı bir farklılık bulunmamaktadır (Tablo 3).

Tablo 3. Bireylerin besin bağımlılığına sahip olma durumuna göre antropometrik ölçümleri ve biyokimyasal parametreleri

\begin{tabular}{|c|c|c|c|c|c|}
\hline & $\begin{array}{c}\text { Besin bağımlılığı var } \\
(\mathrm{n}: 28)\end{array}$ & $\begin{array}{c}\text { Besin bağımlılı̆ı̆ yok } \\
(\mathbf{n}: 78)\end{array}$ & $\begin{array}{l}\text { Toplam } \\
\text { (n:106) }\end{array}$ & & \\
\hline $\begin{array}{l}\text { Antropometrik ölçümler ve } \\
\text { biyokimyasal parametreler }\end{array}$ & $\begin{array}{c}\mathrm{X} \pm \mathrm{SS} \\
\text { Ortanca }(\mathrm{IQR}) \\
\end{array}$ & $\begin{array}{c}\mathrm{X} \pm \mathrm{SS} \\
\text { Ortanca }(\mathrm{IQR}) \\
\end{array}$ & $\begin{array}{c}\mathrm{X} \pm \mathrm{SS} \\
\text { Ortanca (IQR) }\end{array}$ & $t / Z$ & $\mathbf{p}$ \\
\hline Vücut ağırlığı (kg) & $\begin{array}{c}76,9 \pm 15,86 \\
72,9(19,63)\end{array}$ & $\begin{array}{c}73,6 \pm 12,40 \\
74,1(15,80)\end{array}$ & $\begin{array}{c}74,5 \pm 13,40 \\
73,9(16,90)\end{array}$ & $-0,484$ & $0,629^{b}$ \\
\hline BKİ $\left(\mathbf{k g} / \mathbf{m}^{2}\right)$ & $\begin{array}{c}30,7 \pm 6,07 \\
30,4(8,32)\end{array}$ & $\begin{array}{l}29,3 \pm 6,10 \\
29,0(8,75)\end{array}$ & $\begin{array}{l}29,7 \pm 6,09 \\
29,1(8,24)\end{array}$ & $-1,034$ & $0,904^{2}$ \\
\hline Bel çevresi (cm) & $\begin{array}{l}91,7 \pm 11,43 \\
91,0(16,75)\end{array}$ & $\begin{array}{l}90,1 \pm 13,26 \\
89,5(17,25)\end{array}$ & $\begin{array}{l}90,5 \pm 12,77 \\
90,0(17,00)\end{array}$ & $-0,550$ & $0,583^{\circ}$ \\
\hline Bel/kalça oranı & $\begin{array}{c}0,84 \pm 0,07 \\
0,83(0,13)\end{array}$ & $\begin{array}{c}0,85 \pm 0,09 \\
0,84(0,13)\end{array}$ & $\begin{array}{c}0,85 \pm 0,08 \\
0,84(0,12)\end{array}$ & 0,598 & $0,551^{\circ}$ \\
\hline VYY (\%) & $\begin{array}{c}31,7 \pm 8,19 \\
31,6(14,45)\end{array}$ & $\begin{array}{c}30,8 \pm 7,35 \\
32,3(9,20)\end{array}$ & $\begin{array}{c}31,0 \pm 7,55 \\
32,3(11,38)\end{array}$ & $-0,444$ & $0,657^{\natural}$ \\
\hline YVK (kg) & $\begin{array}{c}48,8 \pm 5,09 \\
47,2(5,35) \\
\end{array}$ & $\begin{array}{r}47,4 \pm 4,44 \\
47,0(5,95) \\
\end{array}$ & $\begin{array}{r}47,8 \pm 4,64 \\
47,0(5,42) \\
\end{array}$ & $-0,907$ & $0,365^{t}$ \\
\hline BMH (kkal) & $\begin{array}{c}1591,0 \pm 183,81 \\
1533,0(214,00) \\
\end{array}$ & $\begin{array}{c}1541,2 \pm 159,00 \\
1531,0(235,75) \\
\end{array}$ & $\begin{array}{c}1554,4 \pm 166,47 \\
1531,5(230,00) \\
\end{array}$ & $-0,957$ & $0,339^{b}$ \\
\hline AKG (mg/dL) & $\begin{array}{c}94,1 \pm 14,26 \\
89,0(15,75)\end{array}$ & $\begin{array}{c}97,7 \pm 35,27 \\
88,5(22,25)\end{array}$ & $\begin{array}{c}96,8 \pm 31,10 \\
89,0(19,25)\end{array}$ & $-0,667$ & $0,505^{\mathrm{t}}$ \\
\hline TK $(\mathrm{mg} / \mathbf{d L})$ & $\begin{array}{l}201,5 \pm 31,95 \\
196,5(44,25)\end{array}$ & $\begin{array}{l}197,4 \pm 46,53 \\
189,5(55,00)\end{array}$ & $\begin{array}{l}198,5 \pm 43,05 \\
192,5(54,25)\end{array}$ & $-0,433$ & $0,666^{\circ}$ \\
\hline LDL-K (mg/dL) & $\begin{array}{l}127,2 \pm 24,16 \\
127,4(30,32)\end{array}$ & $\begin{array}{c}118,3 \pm 37,75 \\
112,6(46,43)\end{array}$ & $\begin{array}{c}120,6 \pm 34,80 \\
119,5(38,68)\end{array}$ & $-1,431$ & $0,157^{\circ}$ \\
\hline HDL-K (mg/dL) & $\begin{array}{c}52,4 \pm 9,32 \\
51,4(12,63)\end{array}$ & $\begin{array}{l}52,9 \pm 13,86 \\
50,6(15,73)\end{array}$ & $\begin{array}{c}52,8 \pm 12,78 \\
51,1(14,90)\end{array}$ & 0,218 & $0,828^{\circ}$ \\
\hline TG $(\mathrm{mg} / \mathrm{dL})$ & $\begin{array}{l}139,1 \pm 62,04 \\
124,0(91,25)\end{array}$ & $\begin{array}{l}145,8 \pm 159,75 \\
118,0(94,25)\end{array}$ & $\begin{array}{l}144,1 \pm 140,41 \\
122,5(93,25)\end{array}$ & $-0,677$ & $0,498^{\mathrm{t}}$ \\
\hline
\end{tabular}

\footnotetext{
${ }^{\mathrm{a}}$ Independent $\mathrm{t}$ test ${ }^{\mathrm{b}}$ Mann Whitney $\mathrm{U}$ testi yapılmıştır.
} 
Katılımcıların antropometrik ölçümleri ve kan lipid profilinin değerlendirilmesi Tablo 4'te gösterilmiştir. Besin bağımlılığı olan bireylerde fazla kilolu ve obez birey oranının daha yüksek; bel çevresi, bel/kalça oranı,
TK, LDL-K ve TG düzeyleri optimal olan bireylerin oranının ise daha düşük olduğu belirlenmiştir $(p>0,05)$ (Tablo 4).

Tablo 4. Katılımcıların antropometrik ölçümleri ve kan lipid profilinin değerlendirilmesi

\begin{tabular}{|c|c|c|c|c|c|c|c|}
\hline \multirow{2}{*}{$\begin{array}{l}\text { Antropometrik } \\
\text { ölçümler ve kan lipid } \\
\text { profili }\end{array}$} & \multicolumn{2}{|c|}{$\begin{array}{c}\text { Besin bağımlılığı } \\
\operatorname{var}(\mathbf{n}: 28)\end{array}$} & \multicolumn{2}{|c|}{$\begin{array}{c}\text { Besin bağımlılığı yok } \\
(\mathbf{n : 7 8})\end{array}$} & \multicolumn{2}{|c|}{$\begin{array}{l}\text { Toplam } \\
\text { (n:106) }\end{array}$} & \multirow[b]{2}{*}{$\begin{array}{l}\chi^{2} \\
\mathbf{p}\end{array}$} \\
\hline & $\mathbf{S}$ & $\%$ & $\mathbf{S}$ & $\%$ & $\mathbf{S}$ & $\%$ & \\
\hline \multicolumn{8}{|l|}{ BKİ (kg/m²) } \\
\hline Zayıf & - & - & 1 & 1,3 & 1 & 0,9 & \multirow{4}{*}{$\begin{array}{r}1,209 \\
0,786^{\mathrm{b}}\end{array}$} \\
\hline Normal & 4 & 14,3 & 17 & 21,8 & 21 & 19,8 & \\
\hline Fazla kilolu & 9 & 32,1 & 24 & 30,8 & 33 & 31,1 & \\
\hline Obez & 15 & 53,6 & 36 & 46,2 & 51 & 48,2 & \\
\hline \multicolumn{8}{|l|}{ Bel çevresi } \\
\hline Optimal & 5 & 17,9 & 15 & 19,2 & 20 & 18,9 & \multirow{3}{*}{$\begin{array}{l}0,301 \\
0,860^{c}\end{array}$} \\
\hline Risk & 7 & 25,0 & 23 & 29,5 & 30 & 28,3 & \\
\hline Yüksek risk & 16 & 57,1 & 40 & 51,3 & 56 & 52,8 & \\
\hline \multicolumn{8}{|l|}{ Bel/kalça oranı } \\
\hline Optimal & 14 & 50,0 & 42 & 53,8 & 56 & 52,8 & \multirow{2}{*}{$\begin{array}{r}0,122 \\
0,727^{\circ}\end{array}$} \\
\hline Yüksek risk & 14 & 50,0 & 36 & 46,2 & 50 & 47,2 & \\
\hline \multicolumn{8}{|l|}{ TK } \\
\hline Optimal & 15 & 53,6 & 45 & 57,7 & 60 & 56,6 & \multirow{2}{*}{$\begin{array}{c}0,142 \\
0,706^{\mathrm{c}}\end{array}$} \\
\hline Yüksek risk & 13 & 46,4 & 33 & 42,3 & 46 & 43,4 & \\
\hline \multicolumn{8}{|l|}{ LDL-K } \\
\hline Optimal & 15 & 53,6 & 52 & 66,7 & 67 & 63,2 & \multirow{2}{*}{$\begin{array}{r}1,519 \\
0,218^{\mathrm{c}}\end{array}$} \\
\hline Yüksek risk & 13 & 46,4 & 26 & 33,3 & 39 & 36,8 & \\
\hline \multicolumn{8}{|l|}{ HDL-K } \\
\hline Düşük & 3 & 10,7 & 11 & 14,4 & 14 & 13,2 & \multirow{3}{*}{$\begin{array}{c}0,528 \\
0,768^{d}\end{array}$} \\
\hline Optimal & 19 & 67,9 & 47 & 60,3 & 66 & 62,3 & \\
\hline Yüksek risk & 6 & 21,4 & 20 & 25,6 & 26 & 24,5 & \\
\hline \multicolumn{8}{|l|}{ TG } \\
\hline Optimal & 18 & 64,3 & 51 & 65,4 & 69 & 65,1 & \multirow{2}{*}{$\begin{array}{c}0,011^{\circ} \\
0,917^{\circ}\end{array}$} \\
\hline Yüksek risk & 10 & 35,7 & 27 & 34,6 & 37 & 34,9 & \\
\hline
\end{tabular}

${ }^{\mathrm{a}}$ Mann Whitney U test ${ }^{\mathrm{b}}$ Fisher-exact kikare testi ${ }^{\mathrm{c}}$ Pearson kikare testi ${ }^{\mathrm{d}}$ Likelihood kikare testi yapılmıştır.

Bireylerin sahip oldukları YFAS alt ölçek sayısının antropometrik ölçümler ve biyokimyasal parametreler ile ilişkisi Tablo 5 'te verilmiştir. Buna göre besin bağımlılı̆̆1 olan, olmayan ve tüm bireylerde sahip olunan alt ölçek sayısı ile antropometrik ölçümler ve biyokimyasal parametreler arasında istatistiksel olarak anlamlı düzeyde bir ilişki bulunmamıştır ( $p>0,05)$ (Tablo 5). Tüm bunlarla birlikte besin bağımlılığı olan bireylerin \%50,0'si pasta/kekin, \%46,3'ü çikolatanın, \%32,1'i dondurmanın ve \%28,6'sı şekerin kendilerinde aşırı yeme isteği uyandırması ve/veya belirtilen besinleri aşırı yeme konularında sorun yaşadıklarını ifade etmişlerdir. 
Tablo 5. Bireylerin sahip oldukları YFAS alt ölçek sayısının antropometrik ölçümler ve biyokimyasal bulgular ile ilişkisi

\begin{tabular}{|c|c|c|c|}
\hline & $\begin{array}{c}\text { Besin bağımlılığı var } \\
(\mathbf{n}: 28)\end{array}$ & $\begin{array}{c}\text { Besin bağımlılığı yok } \\
\text { (n:78) }\end{array}$ & Toplam (n:106) \\
\hline $\begin{array}{l}\text { Antropometrik ölçümler ve } \\
\text { biyokimyasal parametreler }\end{array}$ & $\begin{array}{l}\mathbf{r} \\
\mathbf{p}\end{array}$ & $\begin{array}{l}\mathbf{r} \\
\mathbf{p}\end{array}$ & $\begin{array}{l}\mathbf{r} \\
\mathbf{p}\end{array}$ \\
\hline Vücut ağırlığı (kg) & $\begin{array}{l}-0,099 \\
0,616^{\mathrm{b}} \\
\end{array}$ & $\begin{array}{l}-0,062 \\
0,591^{\mathrm{b}} \\
\end{array}$ & $\begin{array}{l}-0,064 \\
0,517^{\mathrm{b}} \\
\end{array}$ \\
\hline BKİ $\left(\mathrm{kg} / \mathrm{m}^{2}\right)$ & $\begin{array}{l}-0,164 \\
0,404^{\mathrm{a}} \\
\end{array}$ & $\begin{array}{r}-0,069 \\
0,550^{\mathrm{a}} \\
\end{array}$ & $\begin{array}{r}-0,078 \\
0,425^{\mathrm{a}} \\
\end{array}$ \\
\hline Bel çevresi (cm) & $\begin{array}{r}-0,049 \\
0,803^{\mathrm{a}} \\
\end{array}$ & $\begin{array}{l}-0,027 \\
0,813^{\mathrm{a}} \\
\end{array}$ & $\begin{array}{l}-0,025 \\
0,800^{\mathrm{a}} \\
\end{array}$ \\
\hline Bel/kalça oranı & $\begin{array}{l}-0,036 \\
0,856^{\mathrm{a}} \\
\end{array}$ & $\begin{array}{l}-0,101 \\
0,378^{b} \\
\end{array}$ & $\begin{array}{l}-0,076 \\
0,437^{\mathrm{a}} \\
\end{array}$ \\
\hline VYY (\%) & $\begin{array}{l}-0,094 \\
0,633^{\mathrm{a}} \\
\end{array}$ & $\begin{array}{r}-0,013 \\
0,908^{\mathrm{b}} \\
\end{array}$ & $\begin{array}{c}0,009 \\
0,928^{\mathrm{a}} \\
\end{array}$ \\
\hline YVK (kg) & $\begin{array}{r}-0,155 \\
0,431^{\mathrm{a}} \\
\end{array}$ & $\begin{array}{l}-0,056 \\
0,625^{\mathrm{a}} \\
\end{array}$ & $\begin{array}{l}-0,071 \\
0,467^{\mathrm{b}} \\
\end{array}$ \\
\hline BMH (kkal) & $\begin{array}{l}-0,089 \\
0,440^{\mathrm{a}} \\
\end{array}$ & $\begin{array}{r}-0,159 \\
0,418^{\mathrm{a}} \\
\end{array}$ & $\begin{array}{r}-0,099 \\
0,313^{b} \\
\end{array}$ \\
\hline AKG (mg/dL) & $\begin{array}{c}0,202 \\
0,303^{b}\end{array}$ & $\begin{array}{l}-0,073 \\
0,527^{\mathrm{b}}\end{array}$ & $\begin{array}{l}-0,013 \\
0,895^{\mathrm{b}}\end{array}$ \\
\hline TK (mg/dL) & $\begin{array}{l}-0,222 \\
0,257^{\mathrm{a}}\end{array}$ & $\begin{array}{l}-0,125 \\
0,274^{\mathrm{b}}\end{array}$ & $\begin{array}{l}-0,156 \\
0,111^{\mathrm{a}}\end{array}$ \\
\hline LDL-K (mg/dL) & $\begin{array}{l}-0,213 \\
0,277^{\mathrm{a}} \\
\end{array}$ & $\begin{array}{l}-0,068 \\
0,557^{\mathrm{b}}\end{array}$ & $\begin{array}{l}-0,102 \\
0,298^{\mathrm{a}} \\
\end{array}$ \\
\hline HDL-K (mg/dL) & $\begin{array}{c}0,058 \\
0,771^{\mathrm{a}} \\
\end{array}$ & $\begin{array}{l}-0,189 \\
0,097^{\mathrm{b}} \\
\end{array}$ & $\begin{array}{l}-0,124 \\
0,206^{\mathrm{b}} \\
\end{array}$ \\
\hline TG (mg/dL) & $\begin{array}{l}-0,060 \\
0,760^{\mathrm{a}} \\
\end{array}$ & $\begin{array}{c}-0,054 \\
0,642^{b}\end{array}$ & $\begin{array}{c}-0,015 \\
0,876^{b} \\
\end{array}$ \\
\hline
\end{tabular}

a Pearson korelasyon $\quad{ }^{b}$ Spearman korelasyon testi kullanılmıştır.

Besin bağımlılığg; madde bağımlılığı ve davranışsal bağımlılık kavramlarını birleştirmekle birlikte obezitenin gelişmesine katkıda bulunabilecek belirli süreçleri ve/veya davranışları açıklayan hipotezler kurmayı sağlaması nedeniyle ilgi odağı haline gelmiştir [14]. Yale Besin Bağımlılı̆̆ı Ölçeği, DSM-4'ün madde bağımlılığına ilişkin tanı ölçütlerine dayanarak bağımlılık benzeri yeme davranışının değerlendirilmesi için geliştirilmiş bir ölçektir. Madde bağımlılığı ve bağımlılık tanı kriterleri 2013 yılında birleştirilmiş ve böylece DSM-5'teki madde kullanım bozukluklarının semptom sayısı artmıştır. Ancak yeni eklenen kriterlerin yeme davranışına aktarılabilirliği net bir şekilde bilinmemektedir [15].

Yale Besin Bağımlılığı Ölçeği ve YFAS'ın çeşitli versiyonları, farklı popülasyonlarda çalışılmış ve besin bağımlılığı prevalansına ilişkin çeşitli sonuçlar elde edilmiştir. Öğrencilerde \%5-10, obez bireylerde \%15-25 [15], bariatrik cerrahi geçiren hastalarda \%14-58 [16] ve tıkınırcasına yeme bozukluğu olanlarda \%42-57 [17-18] olmak üzere toplum genelinde $\% 19,9$ oranında besin bağımlılığı görüldüğü belirlenmiştir [19]. Hardy ve ark. [20] tarafından kadınlarla yapılan bir çalışmada \%18,3; hemşirelerle yapılan bir çalışmada \%5,4 [6] oranında belirlenen besin bağımlılı̆g 1 bu araştırmaya katılan kadınların \%26,4'ünde saptanmıştır. Yeme davranışının önemli sağlık sorunlarına neden olması, fiziksel yoksunluk belirtilerine sahip olunması, aç olunmadığ halde belirli yiyecekleri tüketme gibi alt ölçekleri karşılayanların oranı besin bağımlılığı olan bireylerde olmayanlara kıyasla yüksektir ancak bu fark istatistiksel olarak anlamlı bulunmamıştır $(\mathrm{p}>0,05)$ (Tablo 2). Bununla birlikte bu araştırmadaki kadınların en az 3 alt ölçeği karşılama oranı \%87,8 iken Çelebi'nin [21] yaptığ1 çalışmaya katılan kadınlarda bu oran \%80,0'dir.

Obezite, pozitif enerji dengesi nedeniyle vücutta fazla yağ birikiminin gözlendiği multifaktöriyel bir hastalıktır. Fiziksel inaktivite ile birlikte aşırı besin tüketimi pozitif enerji dengesinin oluşmasındaki temel etkenlerdir [10]. $\mathrm{Bu}$ bağlamda besin bağımlılığına neden olacak yağ/şeker/tuz içeriği yüksek besinlerin kompulsif şekilde tüketilmesinin de obezite gelişimine katkıda bulunduğu ifade edilmektedir [22]. Besin bağımlılığı ile ilgili yapılan bazı çalışmalarda, BKİ ile besin bağımlılığ arasında pozitif ilişki saptanırken [10, 23, 24] bazı çalışmalarda ilişki bulunmamıştır [20, 25, 26]. Kadın bireylerle yapılan bir çalışmada, BKİ değeri arttıkça besin bağımlılı̆̆ına sahip olma durumunun istatistiksel olarak anlamlı düzeyde arttığı ancak VYY ile yapılan değerlendirmede böyle bir sonucun olmadığ belirlenmiştir. Bununla birlikte Pedram ve ark. [10] tarafından yapılan çalışmada, besin bağımlılı̆̆ı olan bireylerin vücut ağırlığı, BKİ, bel ve kalça çevresi, bel/kalça oranı, VYY, viseral yağ yüzdesinin besin bağımlılığı olmayanlara kıyasla daha yüksek olduğu saptanmıştır. $\mathrm{Bu}$ araştırmada ise besin bağımlılı̆̆ına 
sahip olma durumuna göre bireylerin antropometrik ölçümleri arasında anlamlı bir farklılık gözlenmezken (Tablo 3) besin bağımlılı̆̆ına sahip olan bireyler arasında fazla kilolu ve obez bireylerin oranının daha yüksek; bel çevresi, bel/kalça oranı, TK, LDL-K ve TG düzeyleri optimal olan bireylerin oranının ise daha düşük olduğu bulunmuştur ( $p>0,05)$ (Tablo 4). Bununla birlikte besin bağımlılı̆̆ 1 olan bireylerde karşılanan alt ölçek sayısı ile antropometrik ölçümler arasında da anlamlı bir ilişki bulunmamıştır (Tablo 5). Bunun nedeninin katılımcıların BKİ değerlerinin homojen dağılım göstermesi olabileceği düşünülmektedir. Masheb ve ark.'nın [27] yaptıkları çalışmada, vücut ağırlığı ve besin bağımlılığı arasındaki ilişkinin net bir şekilde tanımlanamadığ belirtilmiştir. Bu duruma, vücut ağırlığı değerinin sınırlı aralıkta olmasıyla besin bağımlılığı ve BKİ arasında doğrusal olmayan bir ilişkinin gözlenmesi [28] ile vücut ağırlığının geniş bir aralığa sahip olması durumunda besin bağımlılığ 1 tanısı, semptom sayısı gibi parametreler ve BKİ arasında pozitif yönde bir ilişki bulunmasının neden olabileceği ifade edilmektedir [29-32]. Bu bağlamda araştırmaya katılan bireylerin BKİ değerlerinin normal dağılım göstermesi, BKİ düzeyi ile besin bağımlılı̆̆ 1 arasında istatistiksel olarak anlamlı bir ilişki gözlenmemesini (Tablo 3,4) açıklamaktadır. Bu araştırmanın sonuçlarına paralel olarak Meule ve Kübler'in [33] yapmış oldukları çalışmada, besin bağımlılığına sahip olma durumuna göre BKİ düzeyinde anlamlı farklılık saptanmamıştır. Bununla birlikte Gearhardt ve ark.'nın [34] çalışmasında da YFAS skoru ile BKİ arasında istatistiksel olarak anlamlı düzeyde bir ilişki bulunmamıştır.

Besin bağımlılığında sık gözlenen şekerli ve yağlı yiyeceklerin aşırı tüketimi ve bu kişilerin yemek yerken kontrollerini kaybetmeleri, bazı sağlık sorunlarına yol açabilir [35]. Ancak besin bağımlılığ 1 ve biyokimyasal parametreler arasındaki ilişkiyi değerlendiren sınırlı sayıda çalışma bulunmaktadır [22, 26]. Yang ve ark.'nın [22] yaptığı çalışmada, AKG değerleri besin bağımlılığg olan ve olmayan bireyler arasında istatistiksel olarak anlamlı düzeyde farklılık gösterirken $(p<0,05)$; $T K$, LDL-K, HDL-K ve TG değerleri anlamlı farklılık göstermemiştir ( $p>0,05)$. Pedram ve Sun'ın [26] yapmış oldukları çalışmada da besin bağımlılığına sahip olan bireylerle olmayan bireylerin AKG, TK, LDL-K, HDL$\mathrm{K}$ düzeyleri arasında anlamlı farklılık saptanmamıştır. Bu araştırmaya katılan bireyler besin bağımlılı̆̆ına sahip olma durumuna göre değerlendirildiğinde ise biyokimyasal parametreler arasında fark bulunmadığ belirlenmiştir ( $>>0,05)$ (Tablo 3). Bununla birlikte sahip olunan alt ölçek sayısı ile biyokimyasal parametreler arasında istatistiksel olarak anlamlı düzeyde bir ilişki bulunmamıştır (Tablo 5). Bunun nedeni; katılımcıların çoğunluğunun 30-59 yaş aralığında olması, araştırmaya sadece sağlıklı bireylerin dahil edilmesi ve verilerin tek merkezden toplanması dolayısıyla katılımcıların benzer özelliklere ve beslenme alışkanlıklarına sahip olması olabilir.

Fazla yeme eğilimi, madde bağımlılığına benzer nörobiyolojik özelliklere sahiptir [36]. Özellikle tuz, yağ, şeker ve katkı maddeleri içeren besinlerin daha yüksek bağımlılık potansiyeline sahip olduğu ileri sürülmektedir $[37,38]$. Yağlı ve şekerli yiyecekler için hedonik isteğin fazla olmasının anandamid ve endokanabinoidleri içeren nöropeptid ve nöromodülatörlerin artmasıyla ilişkili olabileceği düşünülmektedir [39]. Çelebi'nin [21] yaptığ 1 çalışmada ekmek, çikolata ve pizzanın bireylerde aşırı yeme isteği uyandırdığı ve/veya belirtilen besinleri aşırı yemekten dolayı sorunlara neden olduğu belirlenmiştir. $\mathrm{Bu}$ araştırmaya katılan ve besin bağımlılığ bireylerin ise \%50,0'si pasta/kekin, \%46,3'ü çikolatanın, $\% 32,1$ 'i dondurmanın ve \%28,6's1 şekerin belirtilen sorunlara neden olduğunu ifade etmiştir. Bununla birlikte besin bağımlılığı olan bireylerin haftalık fast-food ve şekerli içecek tüketimi besin bağımlılı̆̆1 olmayan bireylere kıyasla istatistiksel olarak anlamlı düzeyde yüksek bulunmuştur $(\mathrm{p}<0,05)$ (Tablo 1). Lameshow ve ark. [6] tarafından yapılan bir çalışmada, en yüksek besin bağımlılı̆̆ oluşturan besinlerin hamburger, patates kızartması ve pizza olduğu belirlenmiştir $(p<0,05)$.

\section{Sonuc}

Sonuç olarak besin bağımlılığı, sadece obez bireylerde değil toplumun tamamında görülebilen, prevalansı ülkelere, yaş gruplarına ve hastalık durumuna göre değişebilen bir durumdur. Obezitenin etyolojisinde, yeme bağımlılığının ötesinde genetik, davranışsal ve çevresel faktörler bir arada rol oynasa da obezite salgınında besin bağımlılığının potansiyel rolünün değerlendirilmesi önemli bir tartışma konusudur. Özellikle hazır besin zincirlerinin artışı gibi çevresel değişikliklerin obezitenin gelişimine zemin hazırlamaktadır. Ayrıca bazı kişilerin bu tür besinleri tüketmeye karşı aşırı eğilimli olmaları, besin bağımlılı̆̆ kavramının bireysel olarak değerlendirilmesini gerekli kılmaktadır. Bununla birlikte besin bağımlılığının antropometrik ölçümler ve biyokimyasal parametreler üzerinde olumsuz etkilerine yönelik çelişkili veriler bulunmaktadır. Bu nedenle farklı yaş, cinsiyet ve sağlık durumuna sahip bireylerin dahil edildiği geniş kapsamlı longitudinal çalışmaların yapılması, besin bağımlılı̆̆ının obezite gelişimindeki rolünde, obezitenin tedavisinde ve izleminde önemli veriler sağlayabilir.

\section{Referanslar}

1.DSÖ/Dünya Sağlık Örgütü, Obesity and overweight https://www.who.int/news-room/fact-sheets/detail/obesity-andoverweight, 2018 (accessed 25.02.2020).

2.Campana, B, Brasiel, P.G, De Aguiar, A.S, Luquetti, S.C.P.D, Obesity and Food Addiction: Similarities to Drug Addiction, Obesity Medicine, 2019, 16, 100136

3.Lerma-Cabrera, J.M, Carvajal, F, Lopez-Legarrea, P, Food addiction as a new piece of the obesity framework, Nutrition Journal, 2016, 15, 5

4. Belfort-DeAguiar, R.D, Seo, D. Food Cues and Obesity: Overpowering Hormones and Energy Balance Regulation, Current Obesity Report, 2018, 7(2), 122-129.

5. Nunes-Neto, P.R, Köhler, C.A, Schuch, F.B, et al, Food addiction: Prevalence, psychopathological correlates and associations with quality of life in a large sample, Journal of Psychiatric Research, 2018, 96, 145-152. 
6.Lemeshow, A.R, Rimm, E.B, Hasin, D.S, et al, Food and beverage consumption and food addiction among women in the Nurses' Health Studies, Appetite, 2018, 121, 186-197.

7. Schulte, E.M, Tuttle, H.M, Gearhardt, A.N, Belief in Food Addiction and Obesity-Related Policy Support. PLoS One, 2016, 11(1), e0147557.

8.Loxton, N.J, Tipman, R.J, Reward sensitivity and food addiction in women, Appetite, 2017, 115, 28-35.

9. Hauck, C, We1ß, A, Schulte, E.M, Meule, A, Ellrott, T, Prevalence of 'Food Addiction' as Measured with the Yale Food Addiction Scale 2.0 in a Representative German Sample and Its Association with Sex, Age and Weight Categories, Obesity Facts, 2017, 10(1), 12-24.

10. Pedram, P, Wadden, D, Amini, P, et al, Food Addiction: It Prevalence and Significant Association with Obesity in the Genera Population, PLoS ONE, 2013, 8(9), e74832.

11. DSÖ/Dünya Sağlık Örgütü, Waist Circumference and Waist-Hip Ratio: Report of a WHO Expert Consultation. http://apps.who.int/iris/bitstream/10665/44583/1/9789241501491_e ng.pdf, 2011 (accessed 25.02.2020)

12. NIH/Ulusal Sağlık Enstitüsü, ATP III Guidelines At-A-Glance Quick Desk

Reference.

https://www.nhlbi.nih.gov/files/docs/guidelines/atglance.pdf, 2001(accessed 25.02.2020)

13. Gearhardt, A.N, Corbin, W.R, Brownell, K.D, Yale Food Addiction Scale (YFAS), Measurement Instrument Database for the Socia Science. http://www.midss.org/content/yale-food-addiction-scaleyfas, 2012 (accessed 25.02.2020).

14. Hebebrand, J, Albayrak, Ö, Adan, R, et al, "Eating addiction", rather than "food addiction", better captures addictive-like eating behavior, Neuroscience \& Biobehavioral Reviews, 2014, 47, 295-306.

15. Meule, A, Gearhardt, A,N, Food addiction in the light of DSM-5, Nutrients, 2014, 6(9), 3653-3671.

16. Ivezaj, V, Wiedemann, A.A, Grilo, C.M, Food addiction and bariatric surgery: a systematic review of the literature, Obesity Reviews, 2017, 18(12), 1386-97.

17. Gearhardt, A.N, White, M.A, Masheb, R.M, Morgan, P.T, Crosby, R.D, Grilo, C.M, An examination of the food addiction construct in obese patients with binge eating disorder, International Journal of Eating Disorder, 2012, 45(5), 657-63.

18. Gearhardt, A.N, White, M.A, Masheb, R.M, Grilo, C.M, An examination of food addiction in a racially diverse sample of obese patients with binge eating disorder in primary care settings, Comprehensive Psychiatry, 2013, 54(5), 500-5

19. Pursey, K.M, Stanwell, P, Gearhardt, A.N, Collins, C.E, Burrows, T.L, The prevalence of food addiction as assessed by the Yale Food Addiction Scale: a systematic review, Nutrients, 2014, 6(10), 455290.

20. Hardy, R, Fani, N, Jovanovic, T, Michopoulos, V, Food addiction and substance addiction in women: Common clinical characteristics, Appetite, 2018, 120, 367-373

21. Çelebi, C, Obezite Hastalarında Yeme Bağımlılığı, Psikopatoloji ve Kişilik Özelliklerinin Değerlendirilmesi. Marmara Üniversitesi, Tipta Uzmanlık Tezi, İstanbul, 2015.

22. Yang, F, Liu, A, Li, Y, et al, Food addiction in Patients with newly Diagnosed Type 2 Diabetes in Northeast China, Frontiers Endocrinology, 2017, 8, 218.

23. Flint, A.J, Gearhardt, A.N, Corbin, W.R, Brownell, K.D, Field A.E, Rimm, E.B, Food-addiction scale measurement in 2 cohorts of middle-aged and older women, The American Journal of Clinical Nutrition, 2014, 99(3), 578-86.Gearhardt, A.N, Boswell, R.G, White, M.A, The Association of "Food Addiction" with Disordered Eating and Body Mass Index, Eating Behaviors, 2014, 15(3), 427-433.

24. Berenson, A.B, Laz, T.H, Pohlmeier, A.M, Rahman, M, Cunningham, K.A, Prevalence of Food Addiction Among Low-
Income Reproductive-Aged Women, Journal of Women's Health (Larchmt), 2015, 24(9), 740-4.

25. Pedram, P, Sun, G, Hormonal and Dietary Characteristics in Obese Human Subjects with and without Food Addiction, Nutrients, 2015, 7, 223-238.Masheb, R.M, Ruser, C.B, Min, K.M, Bullock, A.J, Dorflinger, L.M, Does food addiction contribute to excess weight among clinic patients seeking weight reduction? Examination of the Modified Yale Food Addiction Survey, Comprehensive Psychiatry, 2018, 84, 1-6.

26. Meule, A, Food addiction and body-mass-index: a non-linear relationship, Medical Hypotheses, 2012, 79(4), 508-11.

27. Bégin, C, St-Louis, M, Turmel, S, et al, Does food addiction distinguish a specific subgroup of overweight/obese overeating women, Health, 2012, 4(12A), 1492-9.

28. Eichen, D.M, Lent, M.R, Goldbacher, E, Foster, G.D, Exploration of "food addiction" in overweight and obese treatment-seeking adults, Appetite, 2013, 67, 22-4.

29. Meule, A, Lutz, A, Vogele, C, Kubler, A, Womenwith elevated food addiction symptoms show accelerated reactions, but no impaired inhibitory control, in response to pictures of high-calorie food-cues, Eating Behaviors, 2012, 13(4), 423-8.

30. Meule, A, Heckel, D, Jurowich, C.F, Vogele, C, Kubler, A, Correlates of food addiction in obese individuals seeking bariatric surgery, Clinical Obesity, 2014, 4(4), 228-36.

31. Meule, A, Kübler, A, Food cravings in food addiction: The distinct role of positive reinforcement, Eating Behaviors, 2012, 13(3), 252255.Gearhardt, A.N, Yokum, S, Orr, P.T, Stice, E, Corbin, W.R, Brownell, K.D, Neural correlates of food addiction, Archives of General Psychiatry, 2011, 68(8), 808-816.

32. Pandit, R, de Jong, J.W, Vanderschuren, L.J, Adan, R.A, Neurobiology of overeating and obesity: the role of melanocortins and beyond, European Journal of Pharmacology, 2011, 660, 28-42. Volkow, N.D, Wang, G.J, Tomasi, D, Baler, R.D, The addictive dimensionality of obesity, Biological Psychiatry, 2013, 73(9), 811818.

33. Avena, N.M, Gold, M.S, Food and addiction-sugars, fats and hedonic overeating, Addiction, 2011, 106(7), 1213-1220.

34. Gearhardt, A.N, Grilo, C.M, Dileone, R.J, Brownell, K.D, Potenza M.N, Can food be addictive? Public health and policy implications, Addiction, 2011, 106(7), 1208-1212.

35. Richard, J.M, Castro, D.C, Difeliceantonio, A.G, Robinson, M.J.F, Berridge, K.C, Mapping brain circuits of reward and motivation: In the footsteps of Ann Kelley, Neuroscience \& Biobehavioral Reviews, 2013, 37(0), 1-26.

http://edergi.cbu.edu.tr/ojs/index.php/cbusbed isimli yazarın CBU-SBED başl1kl eseri bu Creative Commons Alıntı-Gayriticari4.0 Uluslararası Lisans1 ile lisanslanmıstır.

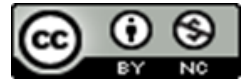

